\title{
Liver histology in hepatitis C infection: a comparison between patients with persistently normal or abnormal transaminases
}

\author{
C J Healey, R W G Chapman, K A Fleming
}

\begin{abstract}
Forty two cases of confirmed hepatitis $C$ virus (HCV) infection with available liver histology were studied. Most patients, 23 of $42(55 \%)$ had abnormal liver function tests but 19 of $42(45 \%)$ had persistently normal liver transaminases (mean aspartate transaminase (AST) $24 \cdot 1 \mathrm{IU} / \mathrm{l}$, mean follow up 10 months). Histological examinations in the group with normal AST activities were normal in two of 19 $(11 \%)$, showed non-specific reactive hepatitis in eight of $19(42 \%)$, chronic persistent hepatitis in six of $19(31 \%)$, and chronic active hepatitis in three of 19 $(16 \%)$. Twenty three of $42(55 \%)$ had either persistently or temporary raised liver transaminases (mean AST 96.2 IU/1, mean follow up 16 months). Histological examinations in this second group with abnormal liver biochemistry showed reactive hepatitis in five of $23(22 \%)$, chronic persistent hepatitis in six of $23(26 \%)$, chronic active hepatitis in 10 of $23(43 \%)$, and cirrhosis in two (9\%). Average alcohol intake was significantly higher in the group within abnormal liver function $(17.8 v 6.4$ units, $p=0.01)$. Although serious pathology was more frequent in the abnormal transaminase group, significant liver pathology (chronic persistent hepatitis or chronic active hepatitis) was found in nine of $19(47 \%)$ of cases with repeatedly normal transaminases. Liver biopsy is advised in all cases of chronic hepatitis $\mathbf{C}$ infection to accurately assess both the degree of fibrosis and the current activity of the disease.
\end{abstract}

(Gut 1995; 37: 274-278)

Keywords: hepatitis C, pathology, aminotransferases.

Department of Gastroenterology, John Radcliffe Hospital, Oxford

C J Healey

R W G Chapman

Nuffield Department of Pathology and Bacteriology,

University of Oxford

K A Fleming

Correspondence to: Dr C J Healey, Department of Gastroenterology, John Radcliffe Hospital, Headley Way, Headington, Oxford OX3 9DU.

Accepted for publication 7 December 1994
The discovery of the hepatitis $C$ virus identified this organism as the cause in the majority of cases with post-transfusion and most cases of sporadic non-A, non-B hepatitis. ${ }^{1-3}$ In addition, the subsequent widespread use of serological tests in screening blood donations and at risk populations had identified many subjects with no or minimal symptoms who are chronically infected by the hepatitis $\mathrm{C}$ virus (HCV)..$^{4}$ The treatment of these patients is controversial as early studies of the natural history of $\mathrm{HCV}$ infection were based on patients with clinically detectable disease and the overall risk of morbidity and mortality in these asymptomatic subjects therefore remains unknown.
In September 1991, screening for HCV of all volunteer blood donations commenced in the United Kingdom and a prevalence for HCV infection of around 1:1500 was found. ${ }^{6-8}$ Many of these patients have now been referred to specialist liver clinics and provide the bulk of the HCV caseload. Most are well or have only minimal symptoms and their liver biochemistry may be normal. As studies among blood donors in Spain ${ }^{4}$ and then Italy ${ }^{9}$ found significant liver pathology in the face of normal liver biochemistry, we have routinely offered liver biopsy to all $\mathrm{HCV}$ infected subjects where either persistent viraemia has been shown by the polymerase chain reaction, or in whom abnormal liver function or clinical disease has been found. In this study, we have compared the histological findings in our patients with persistently normal liver function with patients in whom persistent or temporary increases in liver transaminases were detected, to find out if routine liver function can accurately reflect the liver histology, As a recent study has reported the follow up of blood donors within a UK region, we have analysed our local $\mathrm{HCV}$ positive donors as a subgroup, ${ }^{10}$ to show the proportion of patients referred from the blood transfusion service that come to liver biopsy and the histological results found.

\section{Methods}

Forty two patients were identified from attendance at a gastroenterology clinic in Oxford, who were (a) positive for anti-HCV by second generation ELISA (Abbott Laboratories), (b) had at least three serial estimations of the serum aspartate transaminase (AST) (at least four weeks apart), and (c) had undergone percutaneous liver biopsy. Cases were divided into two groups on the basis of liver biochemistry. Any patient with a transaminase activity above normal $(>45 \mathrm{IU} / \mathrm{l})$ on any occasion during attendance or from results supplied by their general practitioners before referral were defined as abnormal $(n=23)$. Liver function tests taken after the start of treatment with $\alpha$ interferon were not included. The remaining patients all had normal AST on each occasion they were tested $(n=19)$. HCV infection was confirmed in each of these cases by reverse transcription and the polymerase chain reaction, using primers to the $5^{\prime}$ non-coding region. All liver biopsy specimens were assessed by a single experienced liver pathologist (KAF) blinded to the liver biochemistry and scored according to standard criteria ${ }^{11}$ and by Knodell's histological activity index. ${ }^{12}$ For 
TABLE I Summary of histological activity index (HAI) by Knodell's method

\begin{tabular}{|c|c|c|c|c|c|c|c|}
\hline Periportal/bridging necrosis & Score & $\begin{array}{l}\text { Intralobular degeneration } \\
\text { and focal necrosis }\end{array}$ & Score & Portal inflammation & Score & Fibrosis & Score \\
\hline $\begin{array}{l}\text { None } \\
\text { Mild piecemeal necrosis } \\
\text { Moderate piecemeal necrosis } \\
\text { Marked piecemeal necrosis } \\
\text { Moderate piecemeal necrosis + bridging necrosis } \\
\text { Marked piecemeal necrosis + bridging necrosis } \\
\text { Multilobular necrosis }\end{array}$ & $\begin{array}{r}0 \\
1 \\
3 \\
4 \\
5 \\
6 \\
10\end{array}$ & $\begin{array}{l}\text { None } \\
\text { Mild } \\
\text { Moderate } \\
\text { Marked }\end{array}$ & $\begin{array}{l}0 \\
1 \\
3 \\
4\end{array}$ & $\begin{array}{l}\text { No portal inflammation } \\
\text { Mild } \\
\text { Moderate } \\
\text { Marked }\end{array}$ & $\begin{array}{l}0 \\
1 \\
3 \\
4\end{array}$ & $\begin{array}{l}\text { No fibrosis } \\
\text { Fibrous portal expansion } \\
\text { Bridging fibrosis } \\
\text { Cirrhosis }\end{array}$ & $\begin{array}{l}0 \\
1 \\
3 \\
4\end{array}$ \\
\hline
\end{tabular}

$\mathrm{HAI}$ is the combined scores for necrosis, inflammation, and fibrosis.

the purposes of this study, chronic lobular and chronic septal hepatitis were considered to be subgroups of chronic persistent hepatitis. Table I gives a simplified summary of the histological activity index. Details of the indication for referral, parenteral risk factors, estimated time since exposure (defined as the time of blood transfusion or the earliest use of intravenous drugs), and mean AST activity were recorded and compared between the two groups. All available AST values were used in analysis unless patients started any treatment for $\mathrm{HCV}$ infection ( $\alpha$ interferon), at which point no further AST values were recorded. Average intake of alcohol was estimated at time of diagnosis (units/week) and a history of previous high alcohol intake was also recorded. Appropriate statistical analysis was used with a probability value of less than 0.05 being considered significant.

\section{Results}

\section{Patient details}

Forty two cases of HCV infection with available liver histology following percutaneous biopsy were studied. Table II shows indications for referral and risk factors. Patients initially tested after previous intravenous drug use or sexual contacts of known $\mathrm{HCV}$ positive cases were defined as 'at risk'. Clinical disease was defined if investigation was undertaken for either abnormal liver function or for symptoms suggestive of liver disease. Nine of 42 cases had no apparent risk factor and may represent true sporadic infection. Six of seven cases where sexual exposure was a risk factor also admitted to intravenous drug use in the past.

Twenty three of $42(55 \%)$ cases had an abnormal AST activity on one or more occasions. Nineteen of $42(45 \%)$ had persistently normal liver function on at least three occasions separated by at least four weeks and on no occasion had an AST value above the normal limit. Table III shows a comparison of patient details between the groups with normal or abnormal AST activities. No significant difference was found between the two groups with respect to age, sex, or follow up. Length of follow up did tend to be longer in the group with abnormal liver function but did not reach significance $(16.1 v 10.2$ months, $\mathrm{p}=0.09)$. In 32 of $42(76 \%)$ cases the time since exposure could be estimated (mean 13.4 years, range 2-32) and there were no significant differences between the two groups $(11.4 v 13.9$ years, $p=0 \cdot 18$ ). Average intake of alcohol was significantly higher in the group with abnormal liver transaminases $(17.8 v 6.4$ units per week, $\mathrm{p}=0.01$ ) and although a greater proportion in the abnormal group (five of $23 v$ two of 19) also admitted previous heavier alcohol intake, this did not reach significance.

\section{Histological findings}

Standard histological assessment showed normal histology in two, minimal or nonspecific reactive hepatitis in 13 , chronic persistent hepatitis in 12 , chronic active hepatitis in 13, and cirrhosis in two. Figure 1 shows histological diagnosis compared with mean AST. One of two patients with cirrhosis had a high previous alcohol intake, $\alpha$-1-antitrypsin deficiency, and features of both hepatitis $C$ and alcohol related liver damage on biopsy (appreciable iron deposition). Only one other biopsy specimen showed features suggestive of both alcohol and hepatitis C (chronic persistent hepatitis, lymphoid follicles, and Mallory's hyaline). Many of the biopsy specimens showed features typical of hepatitis C. Fatty change was seen in 14 of $42(33 \%)$ and was considerable in five of $42(12 \%)$. Portal lymphoid follicles were seen in seven of $42(17 \%)$. A mild degree of bile duct damage was seen in 16 of $42(38 \%)$ with more severe changes in a further three of $42(7 \%)$. Sinusoidal infiltration was common in 24 of 42 $(57 \%)$. Table IV shows a comparison of the histological diagnoses found between the two groups. Nine of 19 of the cases with normal liver function had either chronic persistent or chronic active hepatitis, with five of 19 showing evidence of fibrosis.

Histological activity index was calculated for each case according to Knodell's method. ${ }^{12}$ This is compared with the histological diagnoses in Fig 2 and shows that higher histological activity index scores are seen with more severe histology. The group with persistently normal liver function had significantly lower histological activity index values on average

TABLE II Referral indication and risk factors in HCV infected patients with persistently normal and abnormal AST activities

\begin{tabular}{lccr}
\hline & $\begin{array}{l}\text { Normal } \\
\text { AST }\end{array}$ & $\begin{array}{l}\text { Abnormal } \\
\text { AST }\end{array}$ & Total \\
\hline $\begin{array}{l}\text { Indication for referral } \\
\text { Blood donor }\end{array}$ & 17 & 9 & 26 \\
At risk & 2 & 6 & 8 \\
Clinical disease & 0 & 8 & 8 \\
Risk factors & & 14 & 22 \\
Intravenous drug use & 8 & 3 & 10 \\
Blood products & 7 & 5 & 7 \\
Sexual contact & 2 & 5 & 9 \\
No risk factor & 4 & & \\
\hline
\end{tabular}

^See Methods for definition of abnormal and normal AST. 
TABLE III Details of patients comparing persistently normal or abnormal AST activities

\begin{tabular}{llll}
\hline & Normal AST & Abnormal $A S T^{\star}$ & $p$ Value \\
\hline Patients (n) & 19 & 23 & \\
Female:male & $11: 8$ & $9: 14$ & NS \\
Age in years (range) & $38 \cdot 9(26-59)$ & $35 \cdot 7(23-50)$ & NS $\neq$ \\
Follow up in months (range) & $10(3-28)$ & $16(3-72)$ & NS \\
Alcohol in units/week (range) & $6 \cdot 4(0-30)$ & $17 \cdot 8(0-60)$ & $0 \cdot 01 \ddagger$ \\
Histological activity index (range) & $3 \cdot 52(0-8)$ & $7 \cdot 13(1-14)$ & $<0 \cdot 001 \ddagger$ \\
Mean AST IU/l (range) & $24 \cdot 1(11 \cdot 5-35 \cdot 0)$ & $96 \cdot 2(25 \cdot 5-204 \cdot 3)$ & $<0 \cdot 001 \neq$ \\
\hline
\end{tabular}

*See Methods for definition of abnormal and normal AST, $+\chi^{2}$ test, $¥$ Student's $t$ test for unpaired data.
(3.5 $v 7 \cdot 1, \mathrm{p}<0.001)$ but there was significant overlap between the range of values (Table III). Histological activity index was also compared with mean AST value, see Fig 3 and shows a weak positive correlation. Knodell's histological activity index can be criticised as it combines both disease activity (necroinflammatory parameters) and stage (fibrosis). However, even when a modified activity index is used (excluding fibrosis) the correlation was no stronger. Of note, eight of $42(19 \%)$ of the biopsy specimens had a histological activity index of greater than five and still had mean AST activities below 45 IU/1.

\section{Blood donors}

The commonest indication for referral was asymptomatic blood donors (in this study 26 of 42). Of these (of whom only nine of 26 had abnormal liver function) two of 26 had normal liver biopsy specimens, 11 of $26 \mathrm{had}$ minimal or non-specific reactive hepatitis, six of 26 had chronic persistent hepatitis, seven of 26 had chronic active hepatitis. A further 11 cases of anti-HCV positive blood donors have been referred to the clinic. Of these, five have repeatedly not attended, three although positive for HCV RNA have declined liver biopsy, and three have repeatedly tested negative for HCV RNA.

\section{Discussion}

Hepatitis $C$ can cause a persistent viral infection. Studies of transfusion related non-A,

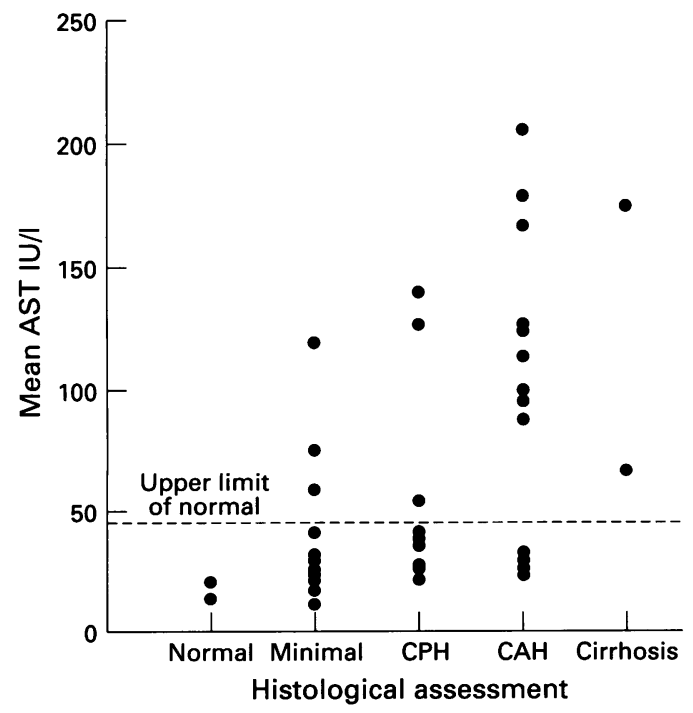

Figure 1: Individual mean AST activities compared with histological assessment in HCV infection. $C P H=$ chronic persistent hepatitis, $C A H=$ chronic active hepatitis.
non-B hepatitis have shown that this infection can result in cirrhosis and even hepatocellular carcinoma. ${ }^{23}$ Since the introduction of HCV screening many asymptomatic subjects have been identified who possess both antibodies against the viral antigens and virus RNA. It is not clear whether such patients will progress to significant liver disease. In this study we have shown that significant liver disease can be found in hepatitis $C$ infection despite persistently normal transaminases (nearly $50 \%$ in our series). Similar findings were reported recently in a smaller number of Italian patients with repeatedly normal liver function over a period of 7-28 months with five of eight $(62 \cdot 5 \%)$ showing either chronic persistent hepatitis or chronic active hepatitis. ${ }^{13}$

Comparison between the two groups (persistently normal or abnormal liver transaminases) identified in this study showed differences. The length of follow up tended to be longer in those with abnormal liver function. This probably reflects that some of this group had symptomatic disease and were identified originally as non- $A$, non-B hepatitis. Also many of the normal group patients were asymptomatic and have only been diagnosed recently following the introduction of blood donor screening. Follow up of cases was curtailed in any patient who started treatment with interferon. Patients with abnormal liver function had significantly higher alcohol intake than those with normal AST activities. This may merely reflect the different indications for liver biopsy between the groups but could also suggest an additive effect of alcohol consumption on the liver transaminase activities in $\mathrm{HCV}$ infection. Two recent studies of alcoholic liver disease and $\mathrm{HCV}$ infection confirmed by HCV RNA detection have further examined this relation. ${ }^{14}{ }^{15}$ Fong et al showed significantly higher liver transaminases and histological activity in HCV RNA positive cases. In the second study, HCV infection was frequently found in alcoholic subjects especially those with either cirrhosis or chronic active hepatitis. These data suggest a significant relation between $\mathrm{HCV}$ and alcohol, reflected in at least the biochemistry and possibly the production of more severe histological changes.

Our study again shows the importance of liver biopsy as the only means of correctly assessing the degree of histological disease in HCV infection, particularly as normal liver function can be found in patients with significant inflammatory activity within the liver. This agrees with the conclusion in a recent paper of the histological findings in $\mathrm{HCV}$ infected UK blood donors. ${ }^{5}$ This view remains

TABLE IV Comparison of histological assessment between both persistently normal and abnormal liver function

\begin{tabular}{llcc}
\hline Histological assessment & $\begin{array}{l}\text { Normal } \\
A S T^{\star}\end{array}$ & $\begin{array}{c}\text { Abnormal } \\
A S T^{\star}\end{array}$ & Total \\
\hline Normal & 2 & 0 & 2 \\
Minimal & 8 & 5 & 13 \\
Chronic persistent hepatitis & 6 & 6 & 12 \\
Chronic active hepatitis & 3 & 10 & 3 \\
Cirrhosis & 0 & 2 & 2 \\
\hline
\end{tabular}

${ }^{\star}$ See Methods for definition of abnormal and normal AST. 


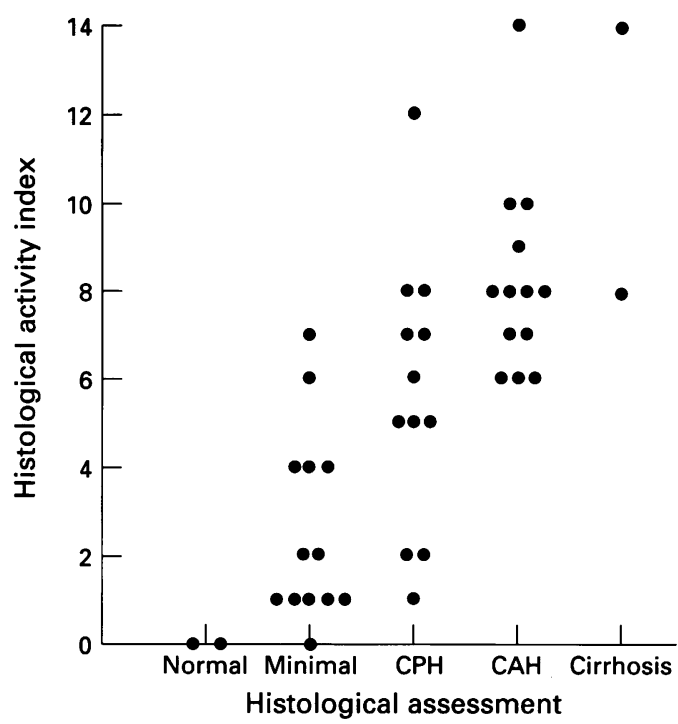

Figure 2: Histological activity index compared with histology in HCV infection. Abbreviations as in Fig 1.

controversial, ${ }^{16}$ however, as it is still not known whether the histological stage indicates or predicts ultimate prognosis and liver biopsy carries a recognised morbidity. The only case control study of the longterm outcome of nonA, non-B hepatitis failed to show any difference in the overall mortality between affected and unaffected matched controls. ${ }^{17}$ Crucially HCV related liver deaths may take longer to manifest that the 18 year follow up. ${ }^{18} 19$ Also, the mean age of cases at the time of exposure (49 years) and the mode of transmission are different to that in our study. The age at exposure is lower (mean 24 years) and possibly reflects the most common risk factor of intravenous drug use. Exposure at a younger age would permit more time for histological progression, as another study showed deterioration of $75 \%$ of repeat liver biopsies with an average follow up of just over two years. ${ }^{20}$ Therefore a significant mortality resulting from $\mathrm{HCV}$ infection among a group of patients exposed to the virus much earlier in adult life cannot be excluded by Seeff's study. ${ }^{17}$

The liver biopsy was normal in only two of 42 of our patients. This confirms the findings



Figure 3: Individual mean AST activity compared with histological activity index in HCV infection. of two earlier Italian studies showing normal liver histology in a few patients who remain $\mathrm{HCV}$ viraemic despite a long period of time since exposure. ${ }^{921}$ While this may represent sampling error inherent in percutaneous liver biopsy, the identification of the HCV genotype and sequence analysis of putative immune epitopes in the viral genome in such patients may aid our understanding of viral persistence and the pathogenic mechanisms in $\mathrm{HCV}$ infection.

The distribution of genotypes around the world and the evolutionary analysis of viral sequences suggest that $\mathrm{HCV}$ has arrived in Western countries within the past 30 years (personal communication, E Holmes). The commonest risk factor in UK cases seems to be intravenous drug use, which is believed to be on the increase. These facts, together with the length of viral persistence, imply that $\mathrm{HCV}$ infection may become an increasing clinical problem if progression occurs commonly. It therefore seems appropriate that continued active assessment and follow up of all infected subjects should be undertaken until the true natural history of this disease is known. ${ }^{22}$ Liver biopsy should be offered as a routine part of this assessment to all cases, as repeatedly normal liver transaminases do not exclude significant liver involvement in many cases. This will allow for identification of patients suitable for antiviral treatments, reassurance of the patients with normal or minimal disease, and intervention in simple lifestyle measures (for example, reduction in alcohol intake and avoidance of hepatotoxic treatment).

1 Alter MJ, Hadler SC, Judson FN, Mares A, Alexander WJ, Hu PY, et al. Risk factors for acute non-A, non-B hepatitis in the United States and association with hepatitis $C$ virus infection. $\mathscr{f} A M A$ 1990; 264: 2231-5.

2 Di Biscelgie A, Goodman ZD, Ishak KG, Hoofnagle JH, Melpolder JJ, Alter HJ. Long-term clinical and histopathological follow-up of chronic posttransfusion hepatitis. Hepatology 1991; 14: 969-74.

3 Tremolada F, Casarin C, Alberti A, Drago C, Tagger A Ribero ML, et al. Long-term follow-up of non-A, non-B (type C) post-transfusion hepatitis. $\mathcal{F}$ Hepatol 1992; 16: 273-81.

4 Esteban JI, Lopez TJ, Genesca J, Madoz P, Viladomiu L, Muniz E, et al. High rate of infectivity and liver disease in blood donors with antibodies to hepatitis C virus. Ann Intern Med 1991; 115: 443-9.

5 Irving WL, Neal KR, Underwood JCE, Simmonds PN, James V. Chronic hepatitis in United Kingdom blood donors infected with hepatitis C virus. $B M M^{\prime} 1994 ; 308$ : 695-6.

6 Seymour C. Asymptomatic infection with hepatitis $C$ virus. BMF 1994; 308: 670-1.

7 McLindon J, Babbs C, Yates A, Love E, McMahon R, Craske J, et al. Asymptomatic blood donors with positive antibodies to hepatitis $C$ virus and chronic liver disease. Gut 1993; 34 (suppl 1): S44.

8 Healey C, Goodrick M, Rouse A, Pearson V, Gray S, Caul $\mathrm{E}$, et al. Epidemiology of HCV infection in blood donors. Gut 1992; 33 (suppl 2): S24.

9 Alberti A, Morsica G, Chemello L, Cavalletto D, Noventa $\mathrm{F}$, Pontisso $\mathrm{P}$, et al. Hepatitis $\mathrm{C}$ viraemia and liver disease F, Pontisso P, et al. Hepatitis C viraemia and liver disease 340: 697-8.

10 Ryan KE, MacLennan S, Barbara JAJ, Hewiit PE. Follow up of blood donors positive for antibodies to hepatitis $C$ virus. BMF 1994; 308: 696-7.

11 Desmet VJ. Chronic hepatitis. In: McGee JO, Isaacson PG, Wright NA, ed. Oxford textbook of pathology. $1 \mathrm{st}$ ed (vol 2a). Oxford: Oxford University Press, 1992: 1313-24.

12 Knodell RG, Ishak KG, Black WC, Chen TS, Craig R Kaplowitz N, et al. Formulation and application of a numerical scoring system for assessing histological activity in asymptomatic chronic active hepatitis. Hepatology 1981; 1: 431-5.

13 Bruno S, Rossi S, Petroni ML, Villa E, Zuin M, Podda $M$. Normal aminotransferase concentrations in patients with antibodies to hepatitis C virus. BMf 1994; 308: 697 . 14 Zignego A, Foshi M, Laff G, Monti M, Careccia G, 
hepatitis $\mathrm{C}$ infection in patients with alcoholic liver disease. Hepatology 1994; 19: 577-82.

15 Fong T, Kanel G, Conrad A, Valinluck B, Charboneau F Adkins R. Clinical significance of concomitant hepatitis $C$ infection in patients with alcoholic liver disease. infection in patients with

Hepatology 1994; 19: 554-7.
16 Valori R, Christie J. Asymptomatic hepatitis C infection. Be cautious with liver biopsy. BMF 1994; 308: 1235 .

17 Seeff LB, Buskell BZ, Wright EC, Durako SJ, Alter HJ, Iber FL, et al. Long-term mortality after transfusion-associated non-A, non-B hepatitis. The National Heart, Lung, and Blood Institute Study Group. N Engl f Med 1992; 327: 1906-11.

18 Yano $M$, Yatsuhashi $H$, Inoue $O$, Inokucki $\mathrm{K}$, Koga $M$.
Epidemiology and long term prognosis of hepatitis $C$ virus infection in Japan. Gut 1993; 34 (suppl 2): W13.

19 Yousuf M, Nakano Y, Tanaka E, Sodeyama T, Kiyosawa $\mathrm{K}$. Persistence of viremia in patients with type-C chronic hepatitis during long-term follow-up. Scand $\mathscr{f}$ Gastroenterol 1992; 27: 812-6.

20 Kim-Deobald J, Bauermeister D, Bredfeldt J, Fenster L, Rosoff L. The histologic progression of mild chronic hepatitis C. Gastroenterology 1993; 104: A946.

21 Brillanti S, Foli M, Gaiani S, Masci C, Miglioli M, Barbara L. Persistent hepatitis $\mathrm{C}$ viraemia without liver disease. Lancet 1993; 341: 464-5.

22 Czaja A. Chronic hepatitis C virus infection - a disease in waiting. N Engl f Med 1992; 327: 1949-50. 